\title{
Tamanho de amostra para estimação da média e do coeficiente de variação em milho
}

\author{
Marcos Toebe ${ }^{(1)}$, Alberto Cargnelutti Filho(1), Cláudia Burin(1), \\ Gabriele Casarotto ${ }^{(2)}$ e Fernando Machado Haesbaert(1)
}

\begin{abstract}
(1)Universidade Federal de Santa Maria, Departamento de Fitotecnia, Avenida Roraima, no 1.000, Bairro Camobi, CEP 97105-900 Santa Maria, RS, Brasil. E-mail: m.toebe@gmail.com, alberto.cargnelutti.filho@gmail.com, clauburin@gmail.com, fhaesbaert@gmail.com (2)Universidade Federal do Rio Grande do Sul, Faculdade de Agronomia, Avenida Bento Gonçalves, no 7.712, Bairro São José, CEP 91540-000 Porto Alegre, RS, Brasil. E-mail: gabrielecasarotto@gmail.com
\end{abstract}

Resumo - O objetivo deste trabalho foi determinar o tamanho de amostra necessário para a estimação da média e do coeficiente de variação em caracteres de híbridos simples, triplo e duplo de milho, em diferentes safras e níveis de precisão, por reamostragem com reposição. Doze caracteres foram mensurados em 361, 373 e 416 plantas, respectivamente, de híbridos simples, triplo e duplo, na safra 2008/2009, e em 1.777, 1.693 e 1.720 plantas, respectivamente, de híbridos simples, triplo e duplo na safra 2009/2010. Calcularam-se as estatísticas descritivas e determinou-se o tamanho de amostra necessário para a estimação da média e do coeficiente de variação, em diferentes níveis de precisão - amplitudes do intervalo de confiança de $95 \%$ (AIC ${ }_{95 \%}$ ) de $5,10, \ldots, 35 \%$ da média e do coeficiente de variação -, por reamostragem com reposição. O tamanho de amostra variou entre híbridos, safras e caracteres. É necessário maior tamanho de amostra para a estimação da média e do coeficiente de variação no híbrido duplo, avaliado na safra 2009/2010. Para um mesmo híbrido, safra, caractere e nível de precisão, é necessário maior tamanho de amostra para a estimação da média, em relação ao necessário para estimação do coeficiente de variação. A mensuração de $325,150,80,60,35$ e 30 plantas, respectivamente, é suficiente para a estimação da média e do coeficiente de variação com $\mathrm{AIC}_{95 \%}$ máximas de $10,15,20,25,30$ e $35 \%$, em todos os híbridos, safras e caracteres.

Termos para indexação: Zea mays, planejamento experimental, reamostragem, tamanho ótimo de parcela.

\section{Sample size for the estimation of the mean and the coefficient of variation in maize}

\begin{abstract}
The objective of this work was to determine the necessary sample size to estimate the mean and the coefficient of variation in traits of single, three-way, and double maize crosses, in different harvests and precision levels, by resampling with replacement. Twelve characters were measured in 361, 373, and 416 plants, respectively, of the single, three-way, and double-cross hybrids of the 2008/2009 crop season, and in 1,777, 1,693 , and 1,720 plants, respectively, of the single, three-way, and double-cross hybrids of the 2009/2010 crop season. Then, descriptive statistics were calculated and the sample size necessary to estimate the mean and coefficient of variation in precision levels - amplitudes of the confidence interval of $95 \%\left(\mathrm{AIC}_{95 \%}\right)$ of $5,10, \ldots$, $35 \%$ of the mean and coefficient of variation - were determined by resampling with replacement. The sample size varied among hybrids, crop seasons, and traits. A larger sample size is necessary to estimate the mean and the coefficient of variation for the double-cross hybrid evaluated in the 2009/2010 crop season. For the same hybrid, crop, trait, and precision level, a larger sample size is necessary to estimate the mean compared to the sample size necessary to estimate the coefficient of variation. The measurement of $325,150,80,60,35$, and 30 plants, respectively, is enough for the estimation of the mean and the coefficient of variation with $\mathrm{AIC}_{95 \%}$ maximum of $10,15,20,25,30$, and $35 \%$, in all hybrids, crops and traits.
\end{abstract}

Index terms: Zea mays, experimental design, resampling, optimum plot size.

\section{Introdução}

A estimativa de produção mundial de milho na safra 2014/2015 é de 906,82 milhões de toneladas, em área de 160,2 milhões de hectares, e o Brasil é o terceiro maior produtor mundial da cultura (Food and Agriculture Organization of the United Nations, 2014). Para que as pesquisas realizadas com a cultura apresentem confiabilidade, é necessário o adequado planejamento experimental, com o correto dimensionamento do

Pesq. agropec. bras., Brasília, v.49, n.11, p.860-871, nov. 2014

DOI: $10.1590 / \mathrm{S} 0100-204 X 2014001100005$ 
tamanho ótimo de parcela, do número de repetições e do tamanho de amostra a ser utilizado, além da escolha de delineamento experimental adequado.

Vários estudos sobre o milho foram desenvolvidos, para determinar o tamanho de amostra a ser utilizado na estimação da média de caracteres como altura de planta, altura de inserção de espiga, peso de espiga, comprimento e diâmetro de espiga, número de fileiras de grãos por espiga, peso e diâmetro de sabugo, número de grãos por fileira, número de grãos por espiga, massa de cem grãos, comprimento de grãos, produtividade de grãos e umidade de grãos (Rosa et al., 2002; Vasić et al., 2003; Martin et al., 2005; Storck et al., 2007; Modolo et al., 2013). Realizaram-se também estudos sobre o milho quanto ao dimensionamento amostral, para avaliar famílias de meios-irmãos (Palomino et al., 2000) e estimar coeficientes de correlação linear de Pearson entre pares de caracteres (Cargnelutti Filho et al., 2010).

Em geral, os estudos realizados indicam variabilidade do tamanho de amostra de acordo com o material utilizado, a safra, o caractere, o local, o manejo, a estatística e o nível de precisão. Assim, Martin et al. (2005) verificaram que o tamanho de amostra é dependente do caractere avaliado na espiga, e observaram também interferências genéticas e ambientais no tamanho de amostra. Os autores constataram que o tamanho de amostra aumentou na seguinte ordem: híbrido simples, variedade cultivada, híbrido duplo e híbrido triplo. De acordo com Storck et al. (2007), o aumento da variabilidade genética de milho, crescente nos híbridos simples, triplos e duplos, não resulta necessariamente em maior tamanho de amostra, assim como constatado por Martin et al. (2005). Ainda de acordo com Storck et al. (2007), para espigas de milho, é necessário maior tamanho de amostra para a mensuração de caracteres de peso, em relação aos caracteres de tamanho e aos provenientes de contagens. Em estudo realizado por Modolo et al. (2013), verificou-se variabilidade do tamanho de amostra entre caracteres de plantas e de espigas de milho, contudo, não se constatou variabilidade de tamanho de amostra entre tipos de manejo de palhada e métodos de semeadura. No entanto, na avaliação de populações sintéticas de milho, Vasić et al. (2003) verificaram variabilidade de tamanho de amostra entre e dentro de ambientes, e recomendaram a avaliação de 100 progênies em mais de um ambiente, para a estimação da média e da variabilidade quanto à produtividade e umidade de grãos.

Embora estudos de dimensionamento amostral para a estimação da média de caracteres de milho já tenham sido realizados (Rosa et al., 2002; Vasić et al., 2003; Martin et al., 2005; Storck et al., 2007; Modolo et al., 2013), a variabilidade do tamanho de amostra entre híbridos, ambientes, safras, caracteres e entre os estudos realizados, sugerem a necessidade de pesquisas complementares. Além disso, não foram encontrados, na literatura, estudos sobre $\mathrm{o}$ dimensionamento amostral necessário para a estimação do coeficiente de variação amostral em caracteres de milho, tendo-se encontrado apenas estudos teóricos de dimensionamento amostral para a estimação de intervalos de confiança do coeficiente de variação (Kelley, 2007; Panichkitkosolkul, 2009; Banik et al., 2012).

Entre os métodos estatísticos empregados para o dimensionamento amostral, tem-se utilizado a reamostragem com reposição, para a determinação do tamanho de amostra necessário para a estimação da média, de coeficientes de correlação, de herdabilidade e de indicadores genéticos em culturas agrícolas (Leite et al., 2009; Cargnelutti Filho et al., 2010, 2012a, 2012b, 2013a, 2013b; Silva et al., 2011). A reamostragem com reposição é recomendada nos casos em que se desconhece a distribuição de probabilidade dos dados (Ferreira, 2009).

O objetivo deste trabalho foi determinar o tamanho de amostra necessário para a estimação da média e do coeficiente de variação, em caracteres de híbridos simples, triplo e duplo de milho, em safras e níveis de precisão, por reamostragem com reposição.

\section{Material e Métodos}

Foram conduzidos dois experimentos com a cultura de milho (Zea mays L.), nas safras agrícolas de 2008/2009 (primeiro experimento) e de 2009/2010 (segundo experimento), na área experimental do Departamento de Fitotecnia, da Universidade Federal de Santa Maria, Santa Maria, RS, a 29 $42^{\prime} \mathrm{S}, 53^{\circ} 49^{\prime} \mathrm{W}$, a $95 \mathrm{~m}$ de altitude. O clima da região de acordo com a classificação de Köppen é do tipo Cfa, subtropical úmido, com verões quentes e sem estação seca definida (Heldwein et al., 2009), e o solo é classificado como 
Argissolo Vermelho distrófico arênico (Santos et al., 2006).

No primeiro experimento, semeado em 26/12/2008, utilizaram-se quatro parcelas com o híbrido simples P32R21, quatro com o híbrido triplo DKB566 e quatro com o híbrido duplo DKB747. No segundo experimento, semeado em 26/10/2009, utilizaramse dezesseis parcelas com o híbrido simples 30F53, dezesseis com o híbrido triplo DKB566 e dezesseis com o híbrido duplo DKB747. Cada parcela foi composta de quatro fileiras de $6 \mathrm{~m}$ de comprimento, espaçadas em $0,80 \mathrm{~m}$, com densidade ajustada para cinco plantas por metro, no total de 62.500 plantas por hectare; Assim, cada parcela foi composta por 120 plantas, no total de 1.440 plantas no primeiro experimento ( 3 híbridos $\times 4$ parcelas por híbrido $\times 120$ plantas por parcela) $\mathrm{e}$ 5.760 plantas no segundo experimento ( 3 híbridos $\times$ 16 parcelas por híbrido $\times 120$ plantas por parcela). Em cada safra, as parcelas dos híbridos simples, triplo e duplo foram casualizados na área experimental. Nos dois experimentos, a adubação de base foi de $750 \mathrm{~kg} \mathrm{ha}^{-1}$ da fórmula 3-24-18 (NPK), e a adubação de cobertura foi de $135 \mathrm{~kg} \mathrm{ha}^{-1} \mathrm{de} \mathrm{N}$, na forma de ureia; os demais tratos culturais foram realizados de acordo com as recomendações para a cultura do milho (Fancelli \& Dourado Neto, 2004).

No primeiro experimento, avaliaram-se 361,373 e 416 plantas, respectivamente, dos híbridos simples, triplo e duplo e, no segundo experimento, 1.777, 1.693 e 1.720 plantas, respectivamente, dos híbridos simples, triplo e duplo. Avaliaram-se apenas plantas que continham os 12 caracteres descritos a seguir. Em razão disso, o número final de plantas avaliadas em cada safra diferiu entre os híbridos simples, triplo e duplo. Portanto, avaliou-se o total de 6.340 plantas e, em cada uma delas mensuraram-se os seguintes caracteres: altura de planta na colheita (AP, cm); altura de inserção de espiga (AIE, cm); peso de espiga (PE, g); número de fileiras de grãos por espiga (NF); comprimento de espiga $(\mathrm{CE}, \mathrm{cm})$; diâmetro de espiga (DE, mm); peso de sabugo (PS, g); diâmetro de sabugo (DS, mm); massa de cem grãos (MCG, em g); número de grãos por espiga (NGR); comprimento de grãos (CGR, em mm); e produtividade de grãos (PROD, g por planta).

Para cada híbrido, em cada experimento, as seguintes estatísticas foram obtidas: mínimo, média, mediana, máximo, desvio-padrão, coeficiente de variação e assimetria de cada caractere. As médias de cada caractere obtidas dos híbridos simples, triplo e duplo das safras 2008/2009 e 2009/2010, foram comparadas duas a duas, pelo teste $t$, para amostras independentes com reamostragem bootstrap (1.000 simulações) a 5\% de probabilidade.

Para cada híbrido em cada experimento, planejaramse 199 tamanhos de amostra, cujo tamanho inicial foi de 10 plantas, e os demais obtidos com o incremento de cinco plantas. Assim, os tamanhos de amostra planejados foram de $\mathrm{n}=10,15,20, \ldots, 1.000$ plantas. Para cada tamanho de amostra planejado, de cada híbrido e experimento obtiveram-se 1.000 reamostras com reposição e, em cada reamostra, foram estimadas a média (x) e o coeficiente de variação $(\mathrm{CV}, \%)$ de cada um dos 12 caracteres. Para cada tamanho de amostra planejado, obtiveram-se, portanto, 1.000 estimativas da média e do coeficiente de variação de cada caractere. Com base nessas 1.000 estimativas de cada estatística (x, CV), determinaram-se o percentil 2,5\%, a média e o percentil 97,5\%, e calculou-se a amplitude do intervalo de confiança de $95 \%\left(\mathrm{AIC}_{95 \%}\right)$, pela diferença entre o percentil $97,5 \%$ e o percentil $2,5 \%$.

Para a determinação do tamanho de amostra (número de plantas) necessário para a estimação da média e do coeficiente de variação de cada um dos 12 caracteres, em cada híbrido e experimento, foram fixados limites máximos de $\mathrm{AIC}_{95 \%}$ da média - 5 (maior precisão), $10,15,20,25,30$ e 35\% (menor precisão) -, e limites máximos fixos de $\mathrm{AIC}_{95 \%}$ do coeficiente de variação 5 (maior precisão), 10, 15, 20, 25, 30 e 35\% (menor precisão). A seguir, partiu-se do tamanho de amostra inicial ( $\mathrm{n}=10$ plantas), e considerou-se como tamanho de amostra adequado (n) o número de plantas a partir do qual a amplitude do intervalo de confiança de 95\% ( $\mathrm{AIC}_{95 \%}$ ) foi menor ou igual ao limite máximo, estabelecido para cada nível de precisão $(5,10, \ldots$, $35 \%$, para a média e para o coeficiente de variação).

Por fim, escolheu-se o híbrido triplo DKB566 da safra 2008/2009, e representou-se graficamente o percentil $2,5 \%$, a média e o percentil $97,5 \%$ da média e do coeficiente de variação, dos caracteres com maior e menor tamanho de amostra estimado para alguns dos tamanhos de amostra planejados $(\mathrm{n}=10,20, \ldots$, 1.000 plantas). As estatísticas (x, CV) dos demais caracteres do híbrido triplo DKB566, avaliado na safra 2008/2009, bem como dos demais híbridos e safras, não foram representadas graficamente, tendo 
considerado o volume de gráficos resultantes e a repetição parcial de dados já apresentados em tabelas. As análises estatísticas foram realizadas com o auxílio do programa R (R Development Core Team, 2014) e do aplicativo Microsoft Office Excel.

\section{Resultados e Discussão}

Para os 12 caracteres mensurados, houve diferenças entre as médias dos híbridos simples, triplo e duplo avaliados nas duas safras (Tabela 1). Em geral, para os híbridos avaliados nas duas safras, os caracteres apresentaram maior amplitude entre os valores mínimos e máximos na safra 2009/2010. Entre os híbridos, o duplo avaliado na safra 2009/2010 apresentou as menores médias em sete dos 12 caracteres mensurados, além de ter apresentado maiores diferenças entre os valores mínimos e máximos, o que indica maior variabilidade deste híbrido. Considerando-se o mesmo híbrido, safra e caractere, as estimativas de média e mediana foram similares. No entanto, constatou-se assimetria em $58(80,56 \%)$ dos 72 casos. A elevada taxa de assimetria pode ser explicada, em parte, pelo elevado número de observações (361 plantas $\leq \mathrm{n} \leq$ 1.777 plantas) consideradas para a verificação da significância da assimetria por meio do teste t. Nesse sentido, conforme descrito por Doane \& Seward (2011) e por Wright \& Herrington (2011), a amplitude do intervalo de confiança da assimetria reduz-se com o aumento do tamanho da amostra e, assim, pequenos desvios de assimetria tornam-se, estatisticamente, significativos.

As médias de comprimento e diâmetro de espiga, massa de cem grãos e de produtividade de grãos (Tabela 1) foram similares às descritas por Martin et al. (2005) para bases genéticas e ambientes, e as médias de diâmetro de espiga e número de fileiras de grãos por espiga foram semelhantes às obtidas por Modolo et al. (2013). Os valores médios de altura de planta à colheita, altura de inserção de espiga, peso de espiga, comprimento e diâmetro de espiga, peso e diâmetro de sabugo, número de grãos por espiga e de produtividade de grãos foram inferiores, e os valores médios de massa de cem grãos, número de fileiras de grãos e de comprimento de grãos foram similares aos obtidos por Storck et al. (2007) em híbridos simples, triplo e duplo de milho. A menor densidade de semeadura no experimento conduzido por Storck et al. (2007), em relação ao presente estudo, pode ter contribuído para o maior crescimento e produtividade de cada planta.

A estimativa de produtividade de grãos foi de $6.178,7.443$ e $7.846 \mathrm{~kg} \mathrm{ha}^{-1}$, respectivamente, para os híbridos simples, triplo e duplo da safra 2008/2009, considerando-se: a área experimental ocupada por híbrido $(4$ parcelas $\times 120$ plantas por parcela $\times$ $0,16 \mathrm{~m}^{2}$ por planta $\left.=76,8 \mathrm{~m}^{2}\right)$; o número de plantas que produziram grãos $(361,373$ e 416 plantas, respectivamente para os híbridos simples, triplo e duplo); e a média de produtividade de grãos $(131,44$, 153,25 e 144,85 g por planta, respectivamente para os híbridos simples, triplo e duplo). Para a safra 2009/2010, a área ocupada por híbrido foi de $307,2 \mathrm{~m}^{2}$ (16 parcelas $\times 120$ plantas por parcela $\times 0,16 \mathrm{~m}^{2}$ por planta $=307,2 \mathrm{~m}^{2}$ ), em que $1.777,1.693$ e 1.720 plantas produziram grãos, respectivamente, nos híbridos simples, triplo e duplo. A média de produtividade de grãos foi de 115,68, 116,62 e 86,37 g por planta, respectivamente, para os híbridos simples, triplo e duplo, o que resultou respectivamente na média de $6.692,6.427$ e $4.836 \mathrm{~kg} \mathrm{ha}^{-1}$ de grãos. Embora a extrapolação dos resultados de produtividade de grãos por planta para a produtividade de grãos por hectare deva ser vista com cautela, destaca-se que, em geral, a produtividade obtida nos híbridos simples, triplo e duplo superou as médias obtidas no Estado do Rio Grande do Sul, de 3.060 e $4.860 \mathrm{~kg} \mathrm{ha}^{-1}$ de grãos, nas safras 2008/2009 e 2009/2010, respectivamente (Companhia Nacional de Abastecimento, 2014).

Em 10 dos 12 caracteres mensurados (83,33\%), verificou-se maior coeficiente de variação para o híbrido duplo DKB747, avaliado na safra 2009/2010 (Tabela 1). Entre os 12 caracteres mensurados nos híbridos simples, triplo e duplo das duas safras, os menores escores de $\mathrm{CV}$ foram verificados quanto à altura de planta, diâmetro de espiga e diâmetro de sabugo $(6,80 \% \leq \mathrm{CV} \leq 12,44 \%)$. Os caracteres número de fileiras de grãos por espiga, altura de inserção de espiga, massa de cem grãos, comprimento de grãos e de espiga apresentaram coeficientes de variação de médios a altos $(11,46 \% \leq \mathrm{CV} \leq 26,35 \%)$ conforme classificação de Gomes (2009). Os caracteres número de grãos por espiga, peso de sabugo, peso de espiga e produtividade de grãos apresentaram maior variabilidade relativa, com valores de $\mathrm{CV}$ classificados como altos ou muito altos $(27,94 \% \leq \mathrm{CV} \leq 46,91 \%)$. Portanto, verificou-se maior variabilidade relativa em caracteres proveninentes 
Tabela 1. Mínimo, média, mediana, máximo, desvio-padrão (DP), coeficiente de variação (CV) e assimetria para 12 caracteres mensurados nos híbridos P32R21 (simples), DKB566 (triplo) e DKB747 (duplo) de milho, na safra 2008/2009, e nos híbridos 30F53 (simples), DKB566 (triplo) e DKB747 (duplo) de milho, na safra 2009/2010

\begin{tabular}{|c|c|c|c|c|c|c|c|c|c|c|c|c|}
\hline \multirow[t]{2}{*}{ Estatística } & \multicolumn{12}{|c|}{ Caracteres mensurados $^{(2)}$} \\
\hline & AP & AIE & PE & $\mathrm{NF}$ & $\mathrm{CE}$ & $\mathrm{DE}$ & PS & DS & MCG & NGR & CGR & PROD \\
\hline & \multicolumn{12}{|c|}{ Híbrido simples P32R21 (n=361 plantas), safra 2008/2009 } \\
\hline Mínimo & 141,00 & 54,00 & 14,00 & 8,00 & 5,60 & 31,00 & 5,00 & 18,00 & 14,90 & 5,00 & 3,00 & 2,00 \\
\hline Média & $212,45 b$ & $96,45 \mathrm{~d}$ & $149,26 b$ & $16,39 \mathrm{a}$ & $14,67 d$ & $48,10 \mathrm{a}$ & $17,81 \mathrm{~d}$ & $25,99 \mathrm{~b}$ & $34,28 \mathrm{a}$ & $377,39 d$ & $11,05 \mathrm{a}$ & $131,44 \mathrm{c}$ \\
\hline Mediana & 215,00 & 98,00 & 152,00 & 16,00 & 14,80 & 49,00 & 17,00 & 26,00 & 34,91 & 394,55 & 11,50 & 135,00 \\
\hline Máximo & 245,00 & 132,00 & 306,00 & 20,00 & 21,10 & 56,00 & 36,00 & 32,00 & 45,49 & 673,00 & 14,00 & 276,00 \\
\hline DP & 15,93 & 12,56 & 59,26 & 2,11 & 2,98 & 4,14 & 5,30 & 2,22 & 4,84 & 144,11 & 1,73 & 55,84 \\
\hline CV (\%) & 7,50 & 13,02 & 39,70 & 12,87 & 20,31 & 8,60 & 29,74 & 8,54 & 14,13 & 38,19 & 15,63 & 42,48 \\
\hline \multirow[t]{2}{*}{ Assimetria } & $-0,89 *$ & $-0,47^{*}$ & $-0,03^{\mathrm{ns}}$ & $-0,71 *$ & $-0,42 *$ & $-1,18^{*}$ & $0,51^{*}$ & $-0,24^{\mathrm{ns}}$ & $-0,61^{*}$ & $-0,29 *$ & $-1,19^{*}$ & $-0,08^{\mathrm{ns}}$ \\
\hline & \multicolumn{12}{|c|}{ Híbrido triplo DKB566 (n=373 plantas), safra 2008/2009 } \\
\hline Mínimo & 150,00 & 68,00 & 15,00 & 8,00 & 5,00 & 30,00 & 4,00 & 18,00 & 16,57 & 6,00 & 3,50 & 2,00 \\
\hline Média & $212,60 \mathrm{~b}$ & $109,57 \mathrm{~b}$ & $168,49 \mathrm{a}$ & $14,43 \mathrm{c}$ & $15,78 \mathrm{~b}$ & $46,44 \mathrm{~b}$ & $15,24 \mathrm{e}$ & $23,95 \mathrm{~d}$ & $32,73 b$ & $466,34 \mathrm{a}$ & $11,25 \mathrm{a}$ & $153,25 \mathrm{a}$ \\
\hline Mediana & 215,00 & 110,00 & 170,00 & 14,00 & 16,20 & 47,00 & 15,00 & 24,00 & 32,80 & 484,29 & 11,50 & 155,00 \\
\hline Máximo & 255,00 & 144,00 & 298,00 & 18,00 & 22,60 & 55,00 & 29,00 & 31,00 & 44,65 & 768,00 & 14,00 & 273,00 \\
\hline $\mathrm{DP}$ & 17,37 & 14,14 & 57,86 & 1,80 & 2,63 & 4,02 & 4,48 & 2,12 & 5,22 & 144,00 & 1,50 & 54,45 \\
\hline $\mathrm{CV}(\%)$ & 8,17 & 12,91 & 34,34 & 12,51 & 16,70 & 8,67 & 29,39 & 8,87 & 15,96 & 30,88 & 13,34 & 35,53 \\
\hline \multirow[t]{2}{*}{ Assimetria } & $-0,65^{*}$ & $-0,38^{*}$ & $-0,34 *$ & $-0,22^{\text {ns }}$ & $-0,84 *$ & $-1,03^{*}$ & $0,20^{\text {ns }}$ & $0,05^{\text {ns }}$ & $-0,23^{\mathrm{ns}}$ & $-0,85^{*}$ & $-1,48^{*}$ & $-0,42 *$ \\
\hline & \multicolumn{12}{|c|}{ Híbrido duplo DKB747 (n=416 plantas), safra 2008/2009 } \\
\hline Mínimo & 135,00 & 45,00 & 23,00 & 10,00 & 5,50 & 31,00 & 6,00 & 18,00 & 16,99 & 30,00 & 3,50 & 10,00 \\
\hline Média & $209,27 \mathrm{c}$ & $110,49 b$ & $173,08 \mathrm{a}$ & $13,99 \mathrm{de}$ & $16,56 \mathrm{a}$ & $45,56 \mathrm{c}$ & $28,23 \mathrm{a}$ & $27,50 \mathrm{a}$ & $34,02 \mathrm{a}$ & $422,23 \mathrm{bc}$ & $9,03 \mathrm{~d}$ & $144,85 b$ \\
\hline Mediana & 210,00 & 110,50 & 177,50 & 14,00 & 17,10 & 46,00 & 28,00 & 28,00 & 34,13 & 440,60 & 9,00 & 149,00 \\
\hline Máximo & 256,00 & 144,00 & 308,00 & 20,00 & 22,60 & 54,00 & 55,00 & 34,00 & 45,87 & 722,00 & 12,50 & 259,00 \\
\hline DP & 17,89 & 13,57 & 54,21 & 1,87 & 3,13 & 3,52 & 9,65 & 2,56 & 4,41 & 117,96 & 1,29 & 46,15 \\
\hline CV (\%) & 8,55 & 12,29 & 31,32 & 13,37 & 18,87 & 7,73 & 34,17 & 9,29 & 12,95 & 27,94 & 14,26 & 31,86 \\
\hline \multirow[t]{2}{*}{ Assimetria } & $-0,67 *$ & $-0,69 *$ & $-0,36^{*}$ & $0,10^{\mathrm{ns}}$ & $-0,68^{*}$ & $-0,72 *$ & $0,13^{\mathrm{ns}}$ & $0,01^{\mathrm{ns}}$ & $-0,40^{*}$ & $-0,55^{*}$ & $-0,61 *$ & $-0,42 *$ \\
\hline & \multicolumn{12}{|c|}{ Híbrido simples 30F53 (n=1.777 plantas), safra 2009/2010 } \\
\hline Mínimo & 160,00 & 80,00 & 8,00 & 6,00 & 4,00 & 17,00 & 4,00 & 11,00 & 15,70 & 7,00 & 1,50 & 2,00 \\
\hline Média & $220,35 \mathrm{a}$ & $121,72 \mathrm{a}$ & $134,95 \mathrm{c}$ & $15,29 b$ & $14,79 \mathrm{~d}$ & $42,74 d$ & $19,27 \mathrm{c}$ & $22,28 \mathrm{e}$ & $27,50 \mathrm{c}$ & $417,33 \mathrm{c}$ & $10,23 b$ & $115,68 \mathrm{~d}$ \\
\hline Mediana & 221,00 & 121,00 & 137,00 & 16,00 & 15,20 & 43,00 & 19,00 & 22,00 & 27,25 & 442,09 & 10,50 & 117,00 \\
\hline Máximo & 255,00 & 162,00 & 287,00 & 20,00 & 22,10 & 53,00 & 41,00 & 34,00 & 44,66 & 809,00 & 14,50 & 249,00 \\
\hline DP & 14,98 & 13,95 & 50,27 & 1,79 & 3,18 & 4,28 & 6,58 & 2,18 & 3,33 & 141,80 & 1,54 & 44,16 \\
\hline CV (\%) & 6,80 & 11,46 & 37,25 & 11,68 & 21,49 & 10,02 & 34,17 & 9,77 & 12,12 & 33,98 & 15,02 & 38,18 \\
\hline \multirow[t]{2}{*}{ Assimetria } & $-0,51^{*}$ & $0,17 *$ & $-0,13^{*}$ & $-0,73 *$ & $-0,48^{*}$ & $-1,13^{*}$ & $0,18^{*}$ & $-0,34^{*}$ & $0,48 *$ & $-0,54 *$ & $-1,35^{*}$ & $-0,15^{*}$ \\
\hline & \multicolumn{12}{|c|}{ Híbrido triplo DKB566 (n=1.693 plantas), safra 2009/2010 } \\
\hline Mínimo & 136,00 & 63,00 & 8,00 & 4,00 & 4,00 & 18,00 & 2,00 & 12,00 & 11,26 & 12,00 & 1,00 & 2,00 \\
\hline Média & $212,56 b$ & $102,17 \mathrm{c}$ & $132,22 \mathrm{c}$ & $13,81 \mathrm{e}$ & $15,46 \mathrm{c}$ & $41,24 \mathrm{e}$ & $15,60 \mathrm{e}$ & $21,89 \mathrm{f}$ & $26,67 d$ & $431,77 b$ & $9,67 \mathrm{c}$ & $116,62 d$ \\
\hline Mediana & 213,00 & 101,00 & 136,00 & 14,00 & 15,70 & 42,00 & 16,00 & 22,00 & 26,70 & 460,67 & 10,00 & 121,00 \\
\hline Máximo & 262,00 & 168,00 & 275,00 & 18,00 & 25,00 & 52,00 & 42,00 & 31,00 & 42,32 & 838,00 & 14,00 & 245,00 \\
\hline $\mathrm{DP}$ & 16,53 & 15,82 & 52,79 & 1,70 & 2,79 & 4,90 & 5,17 & 2,32 & 4,57 & 155,51 & 1,88 & 48,49 \\
\hline CV (\%) & 7,78 & 15,48 & 39,93 & 12,28 & 18,03 & 11,89 & 33,16 & 10,58 & 17,11 & 36,02 & 19,45 & 41,58 \\
\hline \multirow[t]{2}{*}{ Assimetria } & $-0,51 *$ & $0,46^{*}$ & $-0,20 *$ & $-0,47 *$ & $-0,71 *$ & $-1,24^{*}$ & $0,29 *$ & $-0,38^{*}$ & $-0,05^{\text {ns }}$ & $-0,62 *$ & $-1,20 *$ & $-0,24 *$ \\
\hline & \multicolumn{12}{|c|}{ Híbrido duplo DKB747 (n=1.720 plantas), safra 2009/2010 } \\
\hline Mínimo & 135,00 & 51,00 & 4,00 & 4,00 & 2,80 & 15,00 & 1,00 & 11,00 & 10,96 & 7,00 & 1,00 & 2,00 \\
\hline Média & $204,29 d$ & $109,21 \mathrm{~b}$ & $110,08 \mathrm{~d}$ & $14,17 \mathrm{~d}$ & $15,87 b$ & $39,05 \mathrm{f}$ & $23,71 \mathrm{~b}$ & $25,18 \mathrm{c}$ & $25,51 \mathrm{e}$ & $336,22 \mathrm{e}$ & $6,94 \mathrm{e}$ & $86,37 \mathrm{e}$ \\
\hline Mediana & 206,00 & 109,00 & 113,00 & 14,00 & 16,30 & 40,00 & 23,00 & 25,00 & 25,32 & 356,07 & 7,00 & 87,00 \\
\hline Máximo & 258,00 & 164,00 & 275,00 & 22,00 & 28,10 & 51,00 & 67,00 & 35,00 & 43,52 & 825,00 & 12,00 & 219,00 \\
\hline DP & 19,46 & 16,70 & 49,14 & 2,07 & 4,18 & 4,78 & 10,40 & 3,13 & 4,35 & 142,40 & 1,54 & 40,52 \\
\hline CV (\%) & 9,53 & 15,29 & 44,64 & 14,61 & 26,35 & 12,23 & 43,88 & 12,44 & 17,06 & 42,35 & 22,22 & 46,91 \\
\hline Assimetria & $-0,28^{*}$ & $0,05^{\mathrm{ns}}$ & $0,05^{\mathrm{ns}}$ & $-0,35^{*}$ & $-0,34^{*}$ & $-0,98^{*}$ & $0,42 *$ & $-0,51 *$ & $0,12^{*}$ & $-0,32 *$ & $-0,79 *$ & $0,02^{\mathrm{ns}}$ \\
\hline
\end{tabular}

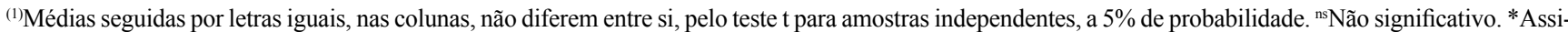
metria difere de zero, por meio do teste $\mathrm{t}$, a $5 \%$ de probabilidade. ${ }^{(2)} \mathrm{AP}$, altura de planta à colheita $(\mathrm{cm})$; AIE, altura de inserção de espiga $(\mathrm{cm}) ; \mathrm{PE}$, peso de espiga (g); NF, número de fileiras de grãos por espiga; CE, comprimento de espiga (cm); DE, diâmetro de espiga (mm); PS, peso de sabugo (g); DS, diâmetro de sabugo (mm); MCG, massa de cem grãos (g); NGR, número de grãos por espiga; CGR, comprimento de grãos (mm); PROD, produtividade de grãos (g por planta). 
de pesagem, em relação aos caracteres obtidos por contagem ou medição, conforme já descrito por Storck et al. (2007) quanto aos híbridos simples, triplo e duplo de milho. Os CVs foram similares aos apresentados por Martin et al. (2005) e, para alguns caracteres, foram superiores aos apresentados por Storck et al. (2007); essa superioridade pode ser explicada, ao menos parcialmente, pelas menores médias em relação ao estudo de Storck et al. (2007).

Para a maioria dos caracteres mensurados, foi necessário maior tamanho de amostra para a estimação da média no híbrido duplo DKB747 da safra 2009/2010, em relação aos demais híbridos avaliados nas safras 2008/2009 e 2009/2010, considerando-se a amplitude do intervalo de confiança de $95 \%\left(\mathrm{AIC}_{95 \%}\right)$ de $5 \%$ da média (Tabela 2). Neste nível de precisão $\left(\mathrm{AIC}_{95 \%} \mathrm{de}\right.$ $5 \%$ da média), verificou-se que menores tamanhos de amostra foram necessários para a estimação da média de altura de planta à colheita ( 35 plantas $\leq \mathrm{n} \leq 55$ plantas $)$, diâmetro de sabugo (50 plantas $\leq \mathrm{n} \leq 95$ plantas) e de espiga (40 plantas $\leq \mathrm{n} \leq 105$ plantas), número de fileiras de grãos por espiga ( 85 plantas $\leq \mathrm{n} \leq 135$ plantas) e altura de inserção de espiga (85 plantas $\leq \mathrm{n} \leq 140$ plantas). Tamanhos de amostra maiores foram necessários para a estimação da média de massa de cem grãos (90 plantas $\leq \mathrm{n} \leq 180$ plantas) e de comprimento de grãos (115 plantas $\leq \mathrm{n} \leq 280$ plantas) e de espiga (155 plantas $\leq n \leq 440$ plantas). Por fim, valores elevados de tamanho de amostra foram requeridos para a mensuração da média de número de grãos por espiga (445 plantas $\leq n \leq 990$ plantas), peso de sabugo (485 plantas $\leq \mathrm{n}>1.000$ plantas) e de espiga (590 plantas $\leq \mathrm{n}>1.000$ plantas) e de produtividade de grãos (590 plantas $\leq \mathrm{n}>1.000$ plantas). Esses resultados apresentaram relação diretamente proporcional aos valores de CV obtidos para cada caractere (Tabela 1). Assim, maiores tamanhos de amostra foram necessários para a estimação da média de caracteres com maiores valores de $\mathrm{CV}$, conforme já constatado em estudos de dimensionamento amostral (Cargnelutti Filho et al., 2012b; Toebe et al., 2014).

Conforme descrito anteriormente, houve diferença de tamanho de amostra necessário para a estimação da média entre caracteres, considerando-se um mesmo híbrido e safra, como pode ser constatado também para os caracteres altura de planta (menor tamanho de amostra) e produtividade de grãos (maior tamanho de amostra), avaliados no híbrido triplo
DKB566 da safra 2008/2009 (Figura 1). Assim, 10 e 40 plantas foram suficientes para a estimação da média de altura de plantas, com a amplitude do intervalo de confiança de $95 \%$ menor ou igual a 35 e $5 \%$ da média, respectivamente (Figura 1 A). Para a estimação da produtividade de grãos, nesses mesmos níveis de precisão, foram necessárias 20 e 720 plantas, respectivamente (Figura $1 \mathrm{~B}$ ). Diferentes tamanhos de amostra para a estimação da média de caracteres de espigas de milho também foram verificadas por Martin et al. (2005), Storck et al. (2007) e Modolo et al. (2013). Em estudo sobre cana-de-açúcar (Leite et al., 2009), macieira (Toebe et al., 2014), mucuna-cinza e feijão-de-porco (Cargnelutti Filho et al., 2012b), a variabilidade do tamanho de amostra também foi constada entre os caracteres. Portanto, deverá ser escolhido o tamanho de amostra adequado, de acordo com o conjunto de caracteres a ser avaliado e o nível de precisão desejado. Também se constatou variabilidade do tamanho de amostra entre híbridos e safras. Em estudos anteriores sobre a cultura do milho, verificou-se que o tamanho de amostra recomendado oscilou de acordo com o material utilizado, a safra, o caractere, o local, o manejo, a estatística avaliada e o nível de precisão desejado (Palomino et al., 2000; Rosa et al., 2002; Martin et al., 2005; Storck et al., 2007; Cargnelutti Filho et al., 2010; Modolo et al., 2013). No presente estudo, a mensuração de 325, 150, 80, 60, 35 e 30 plantas, seria suficiente para a estimação da média com $\mathrm{AIC}_{95 \%}$ máximas respectivamente de 10 , $15,20,25,30$ e $35 \%$ da média, para todos os híbridos, safras e caracteres.

Para a estimação do coeficiente de variação com $\mathrm{AIC}_{95 \%}$ máxima de 5\%, maiores tamanhos de amostras foram requeridos para o híbrido duplo da safra 2009/2010, em oito dos 12 caracteres mensurados (Tabela 3). Esses resultados estão de acordo com a maior variabilidade constatada nesse híbrido, com base nos valores mínimos e máximos e com base nos escores de coeficientes de variação (Tabela 1). Nesse mesmo nível de precisão ( $\mathrm{AIC}_{95 \%}$ de $5 \%$ ), o tamanho de amostra para estimação do CV aumentou na seguinte ordem: altura de planta à colheita (20 plantas $\leq \mathrm{n} \leq 40$ plantas); diâmetro de sabugo ( 25 plantas $\leq \mathrm{n} \leq 80$ plantas); altura de inserção de espiga (35 plantas $\leq \mathrm{n} \leq 95$ plantas); diâmetro de espiga ( 35 plantas $\leq \mathrm{n} \leq 110$ plantas); massa de cem grãos (60 plantas $\leq \mathrm{n} \leq 105$ plantas); número de fileiras de grãos por espiga ( 55 plantas $\leq \mathrm{n} \leq 145$ plantas); 
Tabela 2.Tamanho de amostra (número de plantas) para a estimação da média de doze caracteres de milho, mensurados nos híbridos P32R21 (simples), DKB566 (triplo) e DKB747 (duplo), na safra 2008/2009, e nos híbridos 30F53 (simples), DKB566 (triplo) e DKB747 (duplo), na safra 2009/2010, para amplitudes do intervalo de confiança de 95\% (AIC $95 \%$ ) iguais a $5,10, \ldots, 35 \%$ da média.

\begin{tabular}{|c|c|c|c|c|c|c|c|c|c|c|c|c|}
\hline \multirow[t]{2}{*}{$\mathrm{AIC}_{95 \%}$} & \multicolumn{12}{|c|}{ Caractere $^{(1)}$} \\
\hline & AP & AIE & $\mathrm{PE}$ & NF & $\mathrm{CE}$ & $\mathrm{DE}$ & PS & DS & MCG & NGR & CGR & PROD \\
\hline & \multicolumn{12}{|c|}{ Híbrido simples P32R21, safra 2008/2009 } \\
\hline $5 \%$ & 40 & 100 & 915 & 105 & 250 & 45 & 485 & 50 & 115 & 830 & 140 & $>1.000$ \\
\hline $10 \%$ & 10 & 30 & 225 & 30 & 65 & 15 & 120 & 15 & 30 & 215 & 40 & 260 \\
\hline $15 \%$ & 10 & 15 & 105 & 15 & 30 & 10 & 70 & 10 & 15 & 95 & 20 & 125 \\
\hline $20 \%$ & 10 & 10 & 65 & 10 & 20 & 10 & 35 & 10 & 10 & 60 & 10 & 65 \\
\hline $25 \%$ & 10 & 10 & 40 & 10 & 15 & 10 & 20 & 10 & 10 & 30 & 10 & 50 \\
\hline $30 \%$ & 10 & 10 & 30 & 10 & 10 & 10 & 20 & 10 & 10 & 30 & 10 & 30 \\
\hline \multirow[t]{2}{*}{$35 \%$} & 10 & 10 & 25 & 10 & 10 & 10 & 15 & 10 & 10 & 20 & 10 & 25 \\
\hline & \multicolumn{12}{|c|}{ Híbrido triplo DKB566, safra 2008/2009 } \\
\hline $5 \%$ & 40 & 105 & 670 & 100 & 155 & 50 & 495 & 55 & 160 & 520 & 115 & 720 \\
\hline $10 \%$ & 15 & 30 & 180 & 25 & 45 & 15 & 120 & 15 & 45 & 130 & 30 & 190 \\
\hline $15 \%$ & 10 & 15 & 80 & 15 & 20 & 10 & 65 & 10 & 20 & 70 & 15 & 85 \\
\hline $20 \%$ & 10 & 10 & 50 & 10 & 15 & 10 & 40 & 10 & 15 & 40 & 10 & 50 \\
\hline $25 \%$ & 10 & 10 & 30 & 10 & 10 & 10 & 20 & 10 & 10 & 30 & 10 & 30 \\
\hline $30 \%$ & 10 & 10 & 20 & 10 & 10 & 10 & 20 & 10 & 10 & 20 & 10 & 20 \\
\hline \multirow[t]{2}{*}{$35 \%$} & 10 & 10 & 15 & 10 & 10 & 10 & 15 & 10 & 10 & 15 & 10 & 20 \\
\hline & \multicolumn{12}{|c|}{ Híbrido duplo DKB747, safra 2008/2009 } \\
\hline $5 \%$ & 45 & 90 & 590 & 110 & 210 & 40 & 680 & 55 & 105 & 445 & 130 & 590 \\
\hline $10 \%$ & 15 & 25 & 135 & 35 & 55 & 10 & 175 & 15 & 25 & 120 & 30 & 150 \\
\hline $15 \%$ & 10 & 15 & 70 & 15 & 25 & 10 & 90 & 10 & 15 & 55 & 15 & 70 \\
\hline $20 \%$ & 10 & 10 & 40 & 10 & 15 & 10 & 45 & 10 & 10 & 35 & 10 & 40 \\
\hline $25 \%$ & 10 & 10 & 25 & 10 & 10 & 10 & 30 & 10 & 10 & 20 & 10 & 25 \\
\hline $30 \%$ & 10 & 10 & 20 & 10 & 10 & 10 & 25 & 10 & 10 & 15 & 10 & 20 \\
\hline \multirow[t]{2}{*}{$35 \%$} & 10 & 10 & 15 & 10 & 10 & 10 & 20 & 10 & 10 & 10 & 10 & 15 \\
\hline & \multicolumn{12}{|c|}{ Híbrido simples 30F53, safra 2009/2010 } \\
\hline $5 \%$ & 35 & 85 & 750 & 90 & 290 & 60 & 650 & 55 & 90 & 650 & 140 & 795 \\
\hline $10 \%$ & 10 & 20 & 195 & 20 & 70 & 20 & 170 & 20 & 20 & 170 & 35 & 210 \\
\hline $15 \%$ & 10 & 10 & 95 & 10 & 35 & 10 & 90 & 10 & 15 & 75 & 20 & 95 \\
\hline $20 \%$ & 10 & 10 & 55 & 10 & 20 & 10 & 40 & 10 & 10 & 45 & 10 & 55 \\
\hline $25 \%$ & 10 & 10 & 35 & 10 & 15 & 10 & 35 & 10 & 10 & 35 & 10 & 40 \\
\hline $30 \%$ & 10 & 10 & 25 & 10 & 10 & 10 & 20 & 10 & 10 & 20 & 10 & 25 \\
\hline \multirow[t]{2}{*}{$35 \%$} & 10 & 10 & 20 & 10 & 10 & 10 & 20 & 10 & 10 & 15 & 10 & 20 \\
\hline & \multicolumn{12}{|c|}{ Híbrido triplo DKB566, safra 2009/2010 } \\
\hline $5 \%$ & 40 & 140 & 905 & 85 & 195 & 85 & 635 & 70 & 180 & 760 & 215 & $>1.000$ \\
\hline $10 \%$ & 10 & 35 & 245 & 30 & 45 & 25 & 160 & 20 & 45 & 200 & 55 & 260 \\
\hline $15 \%$ & 10 & 20 & 105 & 10 & 25 & 15 & 75 & 10 & 20 & 95 & 30 & 115 \\
\hline $20 \%$ & 10 & 10 & 60 & 10 & 15 & 10 & 45 & 10 & 15 & 55 & 15 & 70 \\
\hline $25 \%$ & 10 & 10 & 45 & 10 & 10 & 10 & 30 & 10 & 10 & 40 & 10 & 45 \\
\hline $30 \%$ & 10 & 10 & 30 & 10 & 10 & 10 & 20 & 10 & 10 & 25 & 10 & 30 \\
\hline \multirow[t]{2}{*}{$35 \%$} & 10 & 10 & 20 & 10 & 10 & 10 & 15 & 10 & 10 & 20 & 10 & 25 \\
\hline & \multicolumn{12}{|c|}{ Híbrido duplo DKB747, safra 2009/2010 } \\
\hline $5 \%$ & 55 & 140 & $>1.000$ & 135 & 440 & 105 & $>1.000$ & 95 & 170 & 990 & 280 & $>1.000$ \\
\hline $10 \%$ & 15 & 35 & 295 & 30 & 105 & 25 & 265 & 25 & 45 & 250 & 80 & 325 \\
\hline $15 \%$ & 10 & 20 & 130 & 20 & 50 & 10 & 120 & 10 & 20 & 120 & 35 & 150 \\
\hline $20 \%$ & 10 & 10 & 80 & 10 & 30 & 10 & 70 & 10 & 15 & 75 & 20 & 80 \\
\hline $25 \%$ & 10 & 10 & 55 & 10 & 20 & 10 & 50 & 10 & 10 & 50 & 15 & 60 \\
\hline $30 \%$ & 10 & 10 & 35 & 10 & 15 & 10 & 30 & 10 & 10 & 30 & 10 & 35 \\
\hline $35 \%$ & 10 & 10 & 30 & 10 & 10 & 10 & 25 & 10 & 10 & 25 & 10 & 30 \\
\hline
\end{tabular}

${ }^{(1)} \mathrm{AP}$, altura de planta à colheita; AIE, altura de inserção de espiga; $\mathrm{PE}$, peso de espiga; NF, número de fileiras de grãos por espiga; CE, comprimento de espiga; DE, diâmetro de espiga; PS, peso de sabugo; DS, diâmetro de sabugo; MCG, massa de cem grãos; NGR, número de grãos por espiga; CGR, comprimento de grãos; PROD, produtividade de grãos. 
comprimento de espiga (155 plantas $\leq \mathrm{n} \leq 235$ plantas); comprimento de grãos (120 plantas $\leq \mathrm{n} \leq 315$ plantas); peso de sabugo ( 250 plantas $\leq n \leq 680$ plantas); peso de espiga (395 plantas $\leq \mathrm{n} \leq 665$ plantas); produtividade de grãos (410 plantas $\leq \mathrm{n} \leq 685$ plantas); e número de grãos (395 plantas $\leq \mathrm{n} \leq 725$ plantas). Portanto, pode-se destacar que houve diferenças de tamanho de amostra entre os caracteres, como se pode verificar para altura de planta e número de grãos por espiga, no híbrido triplo DKB566 da safra 2008/2009 (Figura 2). Assim, 10 e 25 plantas foram suficientes para a estimação do coeficiente de variação de altura de plantas, com amplitude do intervalo de confiança de $95 \%$ menor ou igual a 35 e 5\%, respectivamente (Figura 2 A). Nos mesmos níveis de precisão (35 e 5\%), foram necessários tamanhos de amostra de 15 e 585 plantas,
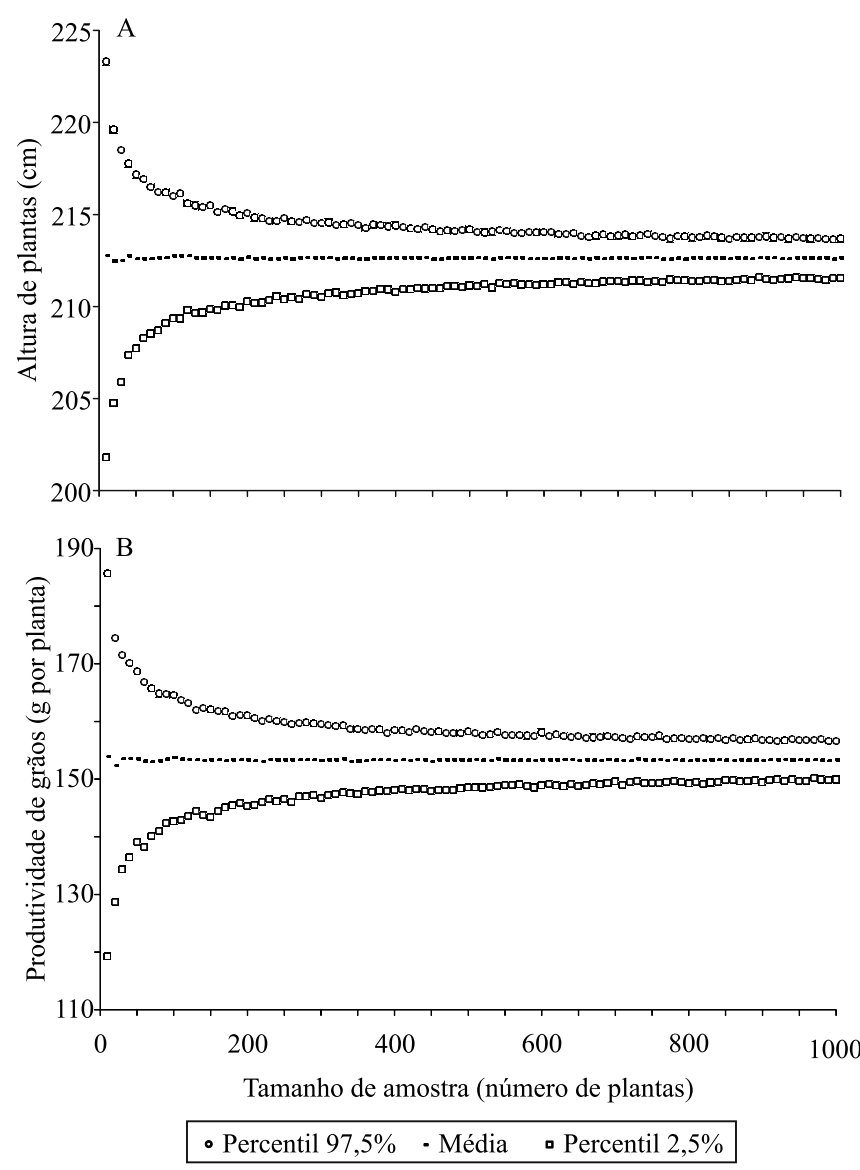

Figura 1. Percentil 2,5\%, média e percentil $97,5 \%$ das mil estimativas da média de: A, altura de plantas; e B, produtividade de grãos para os tamanhos de amostra $\mathrm{n}=10$, $20, \ldots, 1.000$ plantas, no híbrido triplo DKB566, avaliado na safra 2008/2009. para a estimação do coeficiente de variação do número de grãos por espiga, respectivamente (Figura 2 B).

Verificou-se que, para o mesmo nível de precisão, variáveis com maiores valores de CV (Tabela 1) necessitaram de maiores tamanhos de amostra para a estimação do CV (Tabela 3) e vice-versa. Por exemplo, no híbrido simples P32R21 da safra 2008/2009, os maiores e menores valores de CV foram de 42,48 e $7,50 \%$, respectivamente, para a produtividade de grãos e altura de plantas (Tabela 1). Nesse caso, para a estimação do $\mathrm{CV}$ com $\mathrm{AIC}_{95 \%}$ máxima de $5 \%$, o tamanho de amostra é de 670 e 35 plantas, para a produtividade de grãos e altura de plantas respectivamente (Tabela 3). No caso do híbrido triplo DKB566 da safra 2008/2009, a variável altura de plantas apresentou baixo CV $(8,17 \%)$, e o número de grãos por espiga apresentou alto CV (30,88\%) (Tabela 1), tendo sido necessário maior tamanho de amostra para a estimação do $\mathrm{CV}$ do número de grãos (Figura $2 \mathrm{~B}$ ), em relação ao necessário para altura de plantas (Figura 2 A). Esses resultados estão de acordo com estudo realizado por Kelley (2007) para diferentes amplitudes do intervalo de confiança do $\mathrm{CV}$, em que maiores tamanhos de amostra foram requeridos para a estimação nos casos de elevados escores de CV. Assim, de acordo com o autor, para a estimação do CV com $\mathrm{AIC}_{95 \%}$ máxima de $5 \%$, foram necessários tamanhos de amostra de 37 e 656 observações para escores de CV de 10 e 40\%, respectivamente. Esses tamanhos de amostra são similares aos requeridos para a estimação do CV da altura de plantas e da produtividade de grãos, nesse mesmo nível de precisão (Tabela 3), em que os CVs desses caracteres foram próximos de 10 e $40 \%$, respectivamente.

Para um mesmo híbrido, safra e caractere, verificouse que os valores médios de $\mathrm{CV}$, entre os tamanhos de amostra planejados $(\mathrm{n}=10,15, \ldots, 1.000$ plantas $)$, foram similares (Figura 2), o que indica que o aumento do tamanho de amostra não contribuiu para a redução do valor médio de $\mathrm{CV}$, tendo-se verificado somente redução da variabilidade em torno do valor médio de CV. Esses resultados estão de acordo com os obtidos por Rosa et al. (2002), mas são distintos dos verificados por Palomino et al. (2000), em que se verificou tendência de redução do valor médio de $\mathrm{CV}$ com o aumento do tamanho de amostra. Destaca-se, no entanto, que no estudo conduzido por Palomino et al. (2000), foram calculados os coeficientes de variação 
Tabela 3.Tamanho de amostra (número de plantas) para a estimação do coeficiente de variação de doze caracteres de milho, mensurados nos híbridos P32R21 (simples), DKB566 (triplo) e DKB747 (duplo), na safra 2008/2009, e nos híbridos 30F53 (simples), DKB566 (triplo) e DKB747 (duplo), na safra 2009/2010, para amplitudes do intervalo de confiança de 95\% $\left(\mathrm{AIC}_{95 \%}\right)$ iguais a $5,10, \ldots, 35 \%$.

\begin{tabular}{|c|c|c|c|c|c|c|c|c|c|c|c|c|}
\hline \multirow[t]{2}{*}{$\mathrm{AIC}_{95 \%}$} & \multicolumn{12}{|c|}{ Caractere $^{(1)}$} \\
\hline & $\mathrm{AP}$ & AIE & PE & $\mathrm{NF}$ & $\mathrm{CE}$ & $\mathrm{DE}$ & PS & DS & MCG & NGR & CGR & PROD \\
\hline & \multicolumn{12}{|c|}{ Híbrido simples P32R21, safra 2008/2009 } \\
\hline $5 \%$ & 35 & 70 & 565 & 90 & 155 & 50 & 265 & 25 & 100 & 545 & 180 & 670 \\
\hline $10 \%$ & 10 & 20 & 150 & 25 & 45 & 15 & 75 & 10 & 25 & 140 & 50 & 165 \\
\hline $15 \%$ & 10 & 10 & 65 & 10 & 20 & 10 & 35 & 10 & 15 & 65 & 20 & 75 \\
\hline $20 \%$ & 10 & 10 & 40 & 10 & 15 & 10 & 20 & 10 & 10 & 45 & 10 & 50 \\
\hline $25 \%$ & 10 & 10 & 25 & 10 & 10 & 10 & 15 & 10 & 10 & 25 & 10 & 30 \\
\hline $30 \%$ & 10 & 10 & 20 & 10 & 10 & 10 & 10 & 10 & 10 & 20 & 10 & 20 \\
\hline \multirow[t]{2}{*}{$35 \%$} & 10 & 10 & 15 & 10 & 10 & 10 & 10 & 10 & 10 & 15 & 10 & 20 \\
\hline & \multicolumn{12}{|c|}{ Híbrido triplo DKB566, safra 2008/2009 } \\
\hline $5 \%$ & 25 & 60 & 465 & 65 & 180 & 55 & 250 & 35 & 85 & 585 & 175 & 540 \\
\hline $10 \%$ & 10 & 20 & 125 & 20 & 50 & 15 & 70 & 10 & 25 & 150 & 50 & 130 \\
\hline $15 \%$ & 10 & 10 & 55 & 10 & 20 & 10 & 30 & 10 & 10 & 70 & 20 & 60 \\
\hline $20 \%$ & 10 & 10 & 30 & 10 & 15 & 10 & 20 & 10 & 10 & 40 & 10 & 40 \\
\hline $25 \%$ & 10 & 10 & 25 & 10 & 10 & 10 & 15 & 10 & 10 & 30 & 10 & 25 \\
\hline $30 \%$ & 10 & 10 & 15 & 10 & 10 & 10 & 10 & 10 & 10 & 20 & 10 & 20 \\
\hline \multirow[t]{2}{*}{$35 \%$} & 10 & 10 & 15 & 10 & 10 & 10 & 10 & 10 & 10 & 15 & 10 & 15 \\
\hline & \multicolumn{12}{|c|}{ Híbrido duplo DKB747, safra 2008/2009 } \\
\hline $5 \%$ & 40 & 95 & 395 & 55 & 170 & 35 & 355 & 35 & 75 & 395 & 120 & 410 \\
\hline $10 \%$ & 10 & 25 & 100 & 15 & 40 & 10 & 90 & 10 & 20 & 100 & 30 & 115 \\
\hline $15 \%$ & 10 & 10 & 45 & 10 & 20 & 10 & 40 & 10 & 10 & 45 & 15 & 50 \\
\hline $20 \%$ & 10 & 10 & 30 & 10 & 10 & 10 & 30 & 10 & 10 & 30 & 10 & 30 \\
\hline $25 \%$ & 10 & 10 & 20 & 10 & 10 & 10 & 20 & 10 & 10 & 20 & 10 & 20 \\
\hline $30 \%$ & 10 & 10 & 15 & 10 & 10 & 10 & 15 & 10 & 10 & 15 & 10 & 15 \\
\hline \multirow[t]{2}{*}{$35 \%$} & 10 & 10 & 10 & 10 & 10 & 10 & 10 & 10 & 10 & 10 & 10 & 10 \\
\hline & \multicolumn{12}{|c|}{ Híbrido simples 30F53, safra 2009/2010 } \\
\hline $5 \%$ & 20 & 35 & 495 & 80 & 180 & 75 & 355 & 55 & 60 & 540 & 220 & 540 \\
\hline $10 \%$ & 10 & 10 & 130 & 20 & 50 & 20 & 95 & 15 & 15 & 135 & 55 & 145 \\
\hline $15 \%$ & 10 & 10 & 55 & 10 & 20 & 10 & 40 & 10 & 10 & 65 & 25 & 60 \\
\hline $20 \%$ & 10 & 10 & 35 & 10 & 15 & 10 & 25 & 10 & 10 & 40 & 15 & 40 \\
\hline $25 \%$ & 10 & 10 & 20 & 10 & 10 & 10 & 15 & 10 & 10 & 25 & 10 & 25 \\
\hline $30 \%$ & 10 & 10 & 15 & 10 & 10 & 10 & 15 & 10 & 10 & 20 & 10 & 20 \\
\hline \multirow[t]{2}{*}{$35 \%$} & 10 & 10 & 15 & 10 & 10 & 10 & 10 & 10 & 10 & 15 & 10 & 15 \\
\hline & \multicolumn{12}{|c|}{ Híbrido triplo DKB566, safra 2009/2010 } \\
\hline $5 \%$ & 35 & 85 & 560 & 100 & 190 & 110 & 470 & 55 & 95 & 645 & 315 & 645 \\
\hline $10 \%$ & 10 & 25 & 145 & 30 & 45 & 25 & 120 & 15 & 25 & 165 & 85 & 160 \\
\hline $15 \%$ & 10 & 10 & 70 & 15 & 20 & 15 & 55 & 10 & 15 & 75 & 35 & 85 \\
\hline $20 \%$ & 10 & 10 & 40 & 10 & 15 & 10 & 30 & 10 & 10 & 55 & 20 & 45 \\
\hline $25 \%$ & 10 & 10 & 30 & 10 & 10 & 10 & 20 & 10 & 10 & 30 & 15 & 30 \\
\hline $30 \%$ & 10 & 10 & 20 & 10 & 10 & 10 & 15 & 10 & 10 & 25 & 10 & 20 \\
\hline \multirow[t]{2}{*}{$35 \%$} & 10 & 10 & 15 & 10 & 10 & 10 & 10 & 10 & 10 & 15 & 10 & 20 \\
\hline & \multicolumn{12}{|c|}{ Híbrido duplo DKB747, safra 2009/2010 } \\
\hline $5 \%$ & 35 & 70 & 665 & 145 & 235 & 105 & 680 & 80 & 105 & 725 & 305 & 685 \\
\hline $10 \%$ & 10 & 20 & 160 & 35 & 70 & 25 & 180 & 20 & 25 & 195 & 80 & 200 \\
\hline $15 \%$ & 10 & 10 & 90 & 15 & 35 & 15 & 85 & 10 & 15 & 90 & 35 & 95 \\
\hline $20 \%$ & 10 & 10 & 45 & 10 & 20 & 10 & 50 & 10 & 10 & 50 & 20 & 50 \\
\hline $25 \%$ & 10 & 10 & 30 & 10 & 15 & 10 & 30 & 10 & 10 & 35 & 15 & 35 \\
\hline $30 \%$ & 10 & 10 & 20 & 10 & 10 & 10 & 20 & 10 & 10 & 25 & 10 & 30 \\
\hline $35 \%$ & 10 & 10 & 15 & 10 & 10 & 10 & 20 & 10 & 10 & 20 & 10 & 20 \\
\hline
\end{tabular}

${ }^{(1)} \mathrm{AP}$, altura de planta à colheita; AIE, altura de inserção de espiga; PE, peso de espiga; NF, número de fileiras de grãos por espiga; CE, comprimento de espiga; DE, diâmetro de espiga; PS, peso de sabugo; DS, diâmetro de sabugo; MCG, massa de cem grãos; NGR, número de grãos por espiga; CGR, comprimento de grãos; PROD, produtividade de grãos. 
experimentais, obtidos pela divisão da raiz do quadrado médio do erro pela média geral do experimento, de modo distinto ao obtido no presente estudo (coeficiente de variação amostral entre plantas, obtido pela divisão do desvio-padrão pela média). Embora, em muitos estudos, se deseje verificar a interferência do tamanho de amostra na precisão experimental, mediante a análise do coeficiente de variação experimental, destaca-se que o conhecimento do coeficiente de variação amostral é importante na avaliação de caracteres, em estudos de melhoramento de plantas, em levantamentos de dados amostrais e na avaliação de infestações de pragas e doenças, entre outros casos. Em estudo com dados amostrais para híbridos simples, triplo e duplo de milho, Cargnelutti Filho et al. (2010) recomendaram a mensuração de 252 plantas, para a estimação do
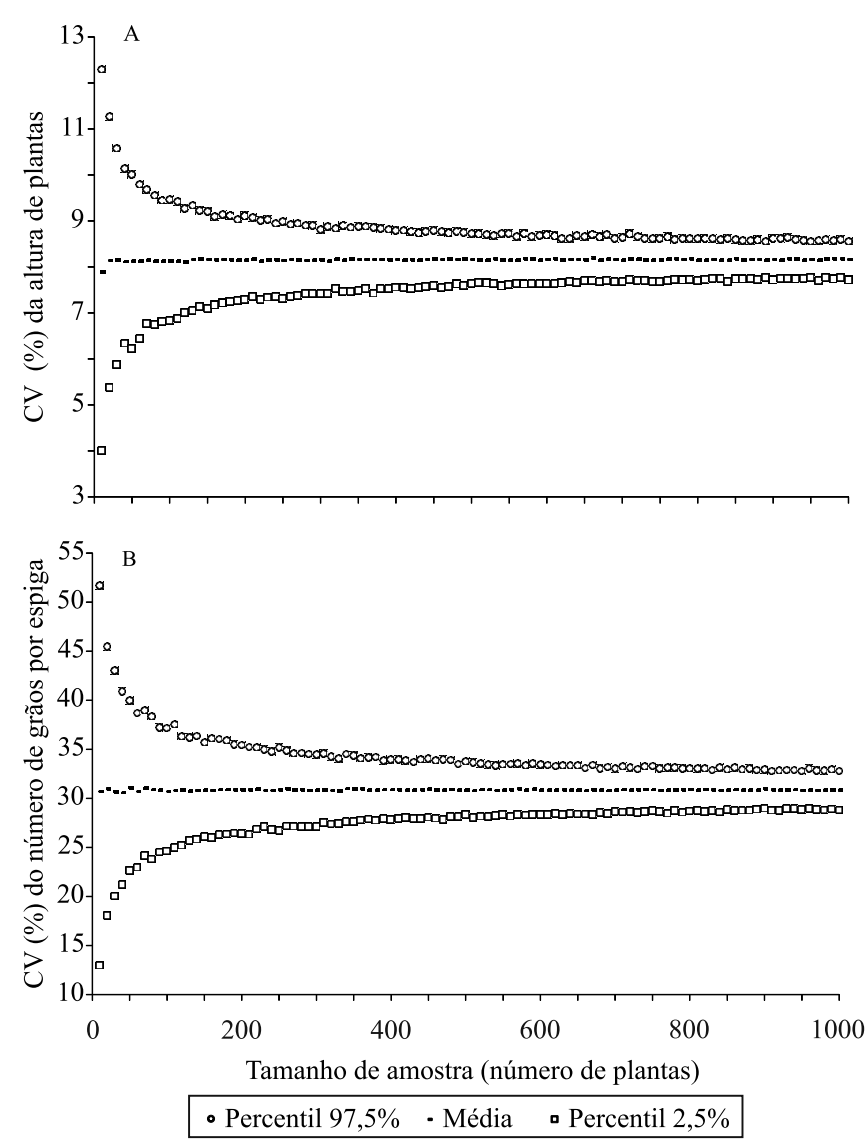

Figura 2. Percentil 2,5\%, média e percentil 97,5\% das mil estimativas do coeficiente de variação $(\mathrm{CV})$ de: A, altura de plantas; e $\mathrm{B}$, número de grãos por espiga, para os tamanhos de amostra $\mathrm{n}=10,20, \ldots, 1.000$ plantas, no híbrido triplo DKB566, avaliado na safra 2008/2009. coeficiente de correlação linear de Pearson com $\mathrm{AIC}_{95 \%}$ igual a 0,30 .

A mensuração de $725,200,95,55,35,30$ e 20 plantas é suficiente para a estimação do $\mathrm{CV}$ com $\mathrm{AIC}_{95 \%}$ máximas de, respectivamente, 5, 10, 15,20,25,30 e 35\%, para todos os híbridos, safras e caracteres (Tabela 3 ). Conforme destacado anteriormente, o tamanho de amostra para a estimação do $\mathrm{CV}$ foi dependente da magnitude do CV de cada caractere, em que o maior CV obtido foi de $46,91 \%$ para a produtividade de grãos do híbrido duplo da safra 2009/2010 (Tabela 1). Nesse sentido, Kelley (2007) indicou tamanhos de amostra de $882,225,104$ e 61 observações, para a estimação do coeficiente de variação de $45 \%$, com $\mathrm{AIC}_{95 \%}$ de 5,10 , 15 e $20 \%$, respectivamente.

De maneira geral, verificou-se que, para um mesmo híbrido, safra, caractere e nível de precisão, foi necessário maior tamanho de amostra para a estimação da média, em relação ao tamanho de amostra necessário para a estimação do coeficiente de variação. Assim, os tamanhos de amostra de 325, 150, 80, 60, 35 e 30 plantas - suficientes para a estimação da média em todos os híbridos, safras e caracteres, com $\mathrm{AIC}_{95 \%}$ máximas de, respectivamente, $10,15,20,25,30$ e $35 \%$ da média (Tabela 2) -, foram maiores que os tamanhos de amostra necessários para a estimação do CV, nesses mesmos níveis de precisão de, respectivamente, 200 , $95,55,35,30$ e 20 plantas (Tabela 3). De modo geral, o correto dimensionamento do tamanho de amostra para a estimação da média garante a estimação do $\mathrm{CV}$, com níveis de precisão iguais ou superiores aos obtidos para a estimação da média. Dessa forma, se for conduzido um experimento com cinco tratamentos e quatro repetições (20 parcelas no total), com avaliação de quatro plantas por parcela (80 plantas no total), pode-se estimar a média e o CV de cada caractere, com $\mathrm{AIC}_{95 \%}$ máxima de $20 \%$. No entanto, para isso, deve-se excluir o efeito de tratamento e de controle local associados a cada observação, para possibilitar a estimação sem a interferência dos efeitos de tratamentos e de blocos que podem contribuir para o aumento da variabilidade entre as observações (plantas). Se houver tratamentos com quatro repetições, e se forem avaliadas 20 plantas por repetição ( 80 plantas por tratamento), poderá ser estimada a média e o CV de cada caractere, em cada tratamento, com $\mathrm{AIC}_{95 \%}$ máxima de $20 \%$, desde que o efeito de controle local, como efeito de blocos, seja retirado da análise.

Pesq. agropec. bras., Brasília, v.49, n.11, p.860-871, nov. 2014 DOI: $10.1590 / \mathrm{S} 0100-204 X 2014001100005$ 


\section{Conclusões}

1. Em geral, é necessário maior tamanho de amostra para a estimação da média e do coeficiente de variação, no híbrido duplo DKB747, na safra 2009/2010.

2. Para um mesmo híbrido, safra, caractere e nível de precisão, é necessário maior tamanho de amostra para a estimação da média, em relação ao necessário para a estimação do coeficiente de variação.

3. A mensuração de $325,150,80,60,35$ e 30 plantas, é suficiente para a estimação da média e do coeficiente de variação com $\mathrm{AIC}_{95 \%}$ máximas de $10,15,20,25,30$ e $35 \%$, respectivamente, para todos os híbridos, safras e caracteres.

\section{Agradecimentos}

Ao Conselho Nacional de Desenvolvimento Científico e Tecnológico (CNPq) e à Coordenação de Aperfeiçoamento de Pessoal de Nível Superior (Capes), pela concessão de bolsas; aos bolsistas e voluntários, pelo auxílio na condução experimental e na coleta de dados.

\section{Referências}

BANIK, S.; KIBRIA, B.M.G.; SHARMA, D. Testing the population coefficient of variation. Journal of Modern Applied Statistical Methods, v.11, p.325-335, 2012.

CARGNELUTTI FILHO, A.; LOPES, S.J.; BRUM, B.; TOEBE, M.; SILVEIRA, T.R. da; CASAROTTO, G. Tamanho de amostra para a estimação do coeficiente de correlação linear de Pearson entre caracteres de mamoneira. Semina: Ciências Agrárias, v.33, p.953-962, 2012a. DOI: 10.5433/1679-0359.2012v33n3p953.

CARGNELUTTI FILHO, A.; TOEBE, M.; BURIN, C.; FICK, A.L.; ALVES, B.M.; FACCO, G. Tamanho de amostra para a estimação da média do comprimento, diâmetro e massa de sementes de feijão de porco e mucuna cinza. Ciência Rural, v.42, p.1541-1544, 2012b. DOI: 10.1590/S0103-84782012005000057.

CARGNELUTTI FILHO, A.; TOEBE, M.; BURIN, C.; SILVEIRA, T.R. da; CASAROTTO, G. Tamanho de amostra para estimação do coeficiente de correlação linear de Pearson entre caracteres de milho. Pesquisa Agropecuária Brasileira, v.45, p.1363-1371, 2010. DOI: 10.1590/S0100-204X2010001200005.

CARGNELUTTI FILHO, A.; TOEBE, M.; FACCO, G.; SANTOS, G.O. dos; ALVES, B.M.; BOLZAN, A. Sample size for estimation of the plastochron in pigeonpea. European Journal of Agronomy, v.48, p.12-18, 2013a. DOI: 10.1016/j.eja.2013.02.003.

CARGNELUTTI FILHO, A.; TOEBE, M.; LOPES, S.J. Número de folhas e de plantas para estimação da média do índice SPAD em crambe. Bioscience Journal, v.29, p.1084-1091, 2013 b.
COMPANHIA NACIONAL DE ABASTECIMENTO. Séries históricas: milho $1^{\mathrm{a}}$. e $2^{\mathrm{a}}$. safras, 2014. Disponível em: $<$ http://www. conab.gov.br/OlalaCMS/uploads/arquivos/14_09_15_17_42_47_ milhototalseriehist.xls $>$. Acesso em: 10 out. 2014.

DOANE, D.P.; SEWARD, L.E. Measuring skewness: a forgotten statistic? Journal of Statistics Education, v.19, p.1-18, 2011.

FANCELLI, A.L.; DOURADO NETO, D. Produção de milho. 2.ed. Guaíba: Agropecuária, 2004. 360p.

FERREIRA, D.F. Estatística básica. 2.ed. Lavras: UFLA, 2009. $664 \mathrm{p}$.

FOOD AND AGRICULTURE ORGANIZATION OF THE UNITED NATIONS. AMIS statistics. Disponível em: <http:// statistics.amis-outlook.org/data/index.html\#>. Acesso em: 9 abr. 2014.

GOMES, F.P. Curso de estatística experimental. 15.ed. Piracicaba: FEALQ, 2009. 451p.

HELDWEIN, A.B.; BURIOL, G.A.; STRECK, N.A. O clima de Santa Maria. Ciência e Ambiente, v.38, p.43-58, 2009.

KELLEY, K. Sample size planning for the coefficient of variation from the accuracy in parameter estimation approach. Behavior Research Methods, v.39, p.755-766, 2007. DOI: 10.3758/ BF03192966.

LEITE, M.S. de O.; PETERNELLI, L.A.; BARBOSA, M.H.P.; CECON, P.R.; CRUZ, C.D. Sample size for full-sib family evaluation in sugarcane. Pesquisa Agropecuária Brasileira, v.44, p.1562-1574, 2009. DOI:10.1590/S0100-204X2009001200002.

MARTIN, T.N.; STORCK, L.; LÚCIO, A.D.; LORENTZ, L.H. Plano amostral em parcelas de milho para avaliação de atributos de espigas. Ciência Rural, v.35, p.1257-1262, 2005. DOI: 10.1590/ S0103-84782005000600005

MODOLO, A.J.; STORCK, L.; TROGELLO, E.; CASSOL, L.C. Sample size determination for maize plants and cob traits under straw management at sowing. Maydica, v.58, p.151-155, 2013.

PALOMINO, E.C.; RAMALHO, M.A.P.; FERREIRA, D.F. Tamanho da amostra para avaliação de famílias de meios-irmãos de milho. Pesquisa Agropecuária Brasileira, v.35, p.1433-1439, 2000. DOI: 10.1590/S0100-204X2000000700018.

PANICHKITKOSOLKUL, W. Improved confidence intervals for a coefficient of variation of a normal distribution. Thailand Statistician, v.7, p.193-199, 2009.

R DEVELOPMENT CORE TEAM. R: a language and environment for statistical computing. Vienna: R Foundation for Statistical Computing, 2014.

ROSA, S.D.V.F. da; PINHO, É.V.R. von; VIEIRA, M. das G.G.C.; VEIGA, R.D. Efeito do tamanho da amostra sobre alguns parâmetros físicos de espiga de milho e da qualidade fisiológica das sementes. Ciência e Agrotecnologia, v.26, p.57-65, 2002.

SANTOS, H.G. dos; JACOMINE, P.K.T.; ANJOS, L.H.C. dos; OLIVEIRA, V.A. de; OLIVEIRA, J.B. de; COELHO, M.R.; LUMBRERAS, J.F.; CUNHA, T.J.F. (Ed.). Sistema brasileiro de classificação de solos. 2.ed. Rio de Janeiro: Embrapa Solos, 2006. 306p. 
SILVA, A.R. da; RÊGO, E.R. do; CECON, P.R. Tamanho de amostra para caracterização morfológica de frutos de pimenteira. Horticultura Brasileira, v.29, p.125-129, 2011. DOI: 10.1590/ S0102-05362011000100022.

STORCK, L.; LOPES, S.J.; CARGNELUTTI FILHO, A.; MARTINI, L.F.D.; CARVALHO, M.P. de. Sample size for single, double and thee-way hybrid corn ear traits. Scientia Agricola, v.64, p.30-35, 2007. DOI: 10.1590/ S0103-90162007000100005.

TOEBE, M.; BOTH, V.; THEWES, F.R.; CARGNELUTTI FILHO, A.; BRACKMANN, A. Tamanho de amostra para a estimação da média de caracteres de maçã. Ciência Rural, v.44, p.759-767, 2014. DOI: $10.1590 / \mathrm{S} 0103-84782014000500001$.

VASIĆ, N.; IVANOVIĆ, M.; JOCKOVIĆ, D.; PETERNELLI, L.; BEKAVAC, G.; NASTASIĆ, A. Influence of sample size on the estimate of mean value and variability for grain yield and grain moisture in synthetic populations of maize (Zea mays L.). Cereal Research Communications, v.31, p.213-220, 2003.

WRIGHT, D.B.; HERRINGTON, J.A. Problematic standard errors and confidence intervals for skewness and kurtosis. Behavior Research Methods, v.43, p.8-17, 2011. DOI 10.3758/ s13428-010-0044-X.

$\overline{\text { Recebido em } 3 \text { de junho de } 2014 \text { e aprovado em } 22 \text { de outubro de } 2014}$ 